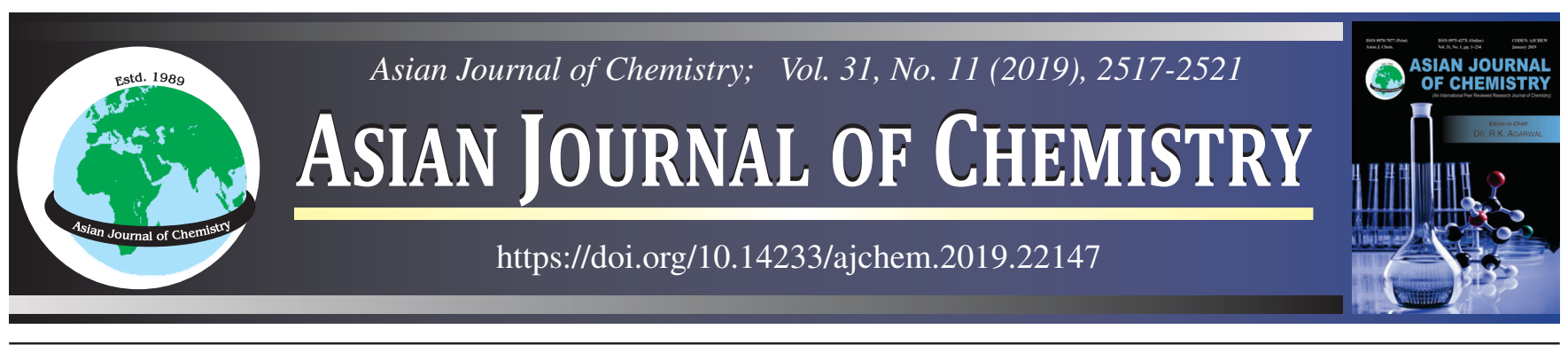

\title{
Effects of Different Extraction Solvent Systems on Total Phenolic, Total Flavonoid, Total Anthocyanin Contents and Antioxidant Activities of Roselle (Hibiscus sabdariffa L.) Extracts
}

\author{
Nguyen Quoc Duy ${ }^{1, *}$, Huynh Anh Thoai ${ }^{1}$, Tri Duc Lam ${ }^{2,3}$ and Xuan Tien Le ${ }^{4}$
}

${ }^{1}$ Faculty of Chemical Engineering and Food Technology, Nguyen Tat Thanh University, Ho Chi Minh City, Vietnam

${ }^{2}$ NTT Hi-Tech Institute, Nguyen Tat Thanh University, Ho Chi Minh City, Vietnam

${ }^{3}$ Center of Excellence for Biochemistry and Natural Products, Nguyen Tat Thanh University, Ho Chi Minh City, Vietnam

${ }^{4}$ Department of Chemical Engineering, HCMC University of Technology, VNU-HCM, Ho Chi Minh City, Vietnam

*Corresponding author: E-mail: nqduy@ntt.edu.vn

Received: 23 April 2019;

Accepted: 7 June 2019;

Published online: 28 September 2019;

AJC-19579

This study aims to investigate the variations in total phenolic content, total anthocyanin content, total flavonoid content and the antioxidant
capacity of Roselle extracts in various extraction solvents. Extracts produced using three solvent systems (methanol, ethanol and acetone)
at three different concentrations $(50,70$ and $90 \%(\mathrm{v} / \mathrm{v})$ ) were compared roselle calyx extract produced using distilled water. The antioxidant
capacities of roselle calyx extracts were evaluated using DPPH free radical-scavenging capacity, ferric reducing antioxidant power (FRAP)
and reducing power. The extraction efficiencies of phenolics, anthocyanins and flavonoids from roselle calyx varied considerably. The
results showed that at $50 \%$, ethanol was the appropriate solvent for extraction of flavonoids, which achieved $508.64 \mathrm{mg} \mathrm{RE} / \mathrm{L}$ and
phenolics, which achieved $762.11 \mathrm{mg} \mathrm{GAE} / \mathrm{L}$, while at $70 \%$, methanol was the effective solvent for extracting anthocyanins, which
achieved $8.404 \mathrm{mg} / \mathrm{L}$. For antioxidant activity, at $50 \%$ for ethanol, $70 \%$ for methanol, 50 and $70 \%$ for acetone were solvents used to
obtain the highest DPPH free radical scavenging activities, ranging from $869.47-927.60 \mu \mathrm{mol}$ TE/L. Thus, at 50 and $70 \%$ for acetone
were determined as solvents which gave extracts with the highest ferric reducing antioxidant power FRAP, ranging from $3493.52-3459.22$
$\mu$ mol TE/L.

Keywords: Extraction solvent, Total phenolic content, Total flavonoid content, Total anthocyanin content, Antioxidant activity.

ᄂ - - - - - - - - - - - - - - - - - - - - - - - - - - - - -

\section{INTRODUCTION}

Hibiscus sabdariffa L. (Roselle calyx) is one of the members of the Malvaceae family, also known as Jamaica flowers which is a medicinal plant grown in Africa, South East Asia, Central America and Mexico [1]. Roselle calyx uses not only as a flavouring for sauces, soft drinks but also as a colourant for foods. In different countries, Roselle calyx plays an important role in folk medicinal plants due to many chemicals have potential health benefits [2]. Moreover, Roselle calyx also promotes cardiovascular health and prevent pyrexia, hypertension and liver disorders. The red varieties of Roselle calyx have antioxidant and cyclooxygenase inhibitory activity. Moreover, Roselle calyx applied in the pharmaceutical and cosmetic industries. In food colours of natural origin, anthocyanins are the most common colours family. Anthocyanin is a watersoluble phenolic compound that functions as a colour from red to dark purple to plants that have long been used as a natural colouring ingredient for food safety. Anthocyanin colourants can be extracted from a variety of materials. Anthocyanins, apart from being recognized as natural plant pigments from the flavonoid family, possess valuable pharmacological properties such as antioxidative, anti-inflammatory and antineurodegenerative effects. Recently, many studies demonstrate the biological activities of anthocyanin including protection from atherosclerosis, antioxidant activity and anticarcinogenic activity. Anthocyanins are common in higher plants but do not exist in some lower plants such as moss and algae. In nature, there are plants containing a single anthocyanin compound while other plants have a mixture of anthocyanins such as peony flower, sugar beet [3]. On the other hand, anthocyanin is a good antioxidant compound due to the effective inhibition of free radicals [4]. Most of the mentioned health benefits of anthocyanins are related to their antioxidant mechanisms [5].

This is an open access journal, and articles are distributed under the terms of the Attribution 4.0 International (CC BY 4.0) License. This license lets others distribute, remix, tweak, and build upon your work, even commercially, as long as they credit the author for the original creation. You must give appropriate credit, provide a link to the license, and indicate if changes were made. 
Thus, anthocyanins have been used in the human diet throughout history [6].

There are different sort of polyphenols such as phenolic acid, flavonoids (flavones, flavanols, isoflavones) and lignans. They are divided into several classes based on the structural elements and the number of phenolic rings in the molecular $[7,8]$. Polyphenol plays an important role in antioxidants in the human diet. The previous study demonstrates that phenolic compounds act as antimutant, metal chelators and antimicrobial agents [9]. Flavonoids belong to a group of metabolites characterized by the diphenylpropane structure which found in vegetables, roots, stem, fruits [10,11]. In natural, more than 4000 types of flavonoids have been classified. They are responsible for the attractive colours of fruits, flowers and leaves [12]. Flavonoids can be divided into difference classes such as flavanones, flavanols, isoflavones, anthocyanidins [12].

The importance of the natural antioxidant in health and food applications have been reported. The anthocyanins in Hibiscus sabdariffa L. has many biological activities beneficial to human health as antioxidant ability, cardiovascular diseases, prevention of asthma [13]. In India, preparations of Roselle calyx or leaves are often used to prevent lethargy, lower fever, blood pressure and blood viscosity [14]. In North Africa, the products form Roselle calyx has been used to cure coughs and sore throats [15]. Furthermore, preparations of Roselle calyx have been applied to cure cardiovascular and neurological diseases in Egypt [16]. Various solvent systems have been applied to extract polyphenols from plant materials $[17,18]$. However, the extraction yield and antioxidant capacity of the plant-derived extracts are highly dependent on the nature of the extracted solvent, due to the presence of various antioxidant compounds of different chemical properties and polarity. There are several methods that are applied to separate polyphenols from plant material. These methods differ in the solvent and conditions used that may affect the content of polyphenols, flavonoids, anthocyanins as well as antioxidant activity of hibiscus extract. Common solvents have been used including ethanol, methanol, acetone and water. Particularly, ethanol and methanol have been applied broadly to extract antioxidant compounds from fruits and vegetables [19].

Previous studies demonstrate that ethyl acetate impact on the extraction of phenolic compounds from citrus peel and onion [20,21]. Hibiscus is known to have high biological activities. Nevertheless, relatively little is explored about the antioxidant capacity of hibiscus extracts. In this study, the effect of extraction solvent systems on total phenolic, total flavonoid, anthocyanin and antioxidant activity of hibiscus extract at different concentrations were determined.

\section{EXPERIMENTAL}

Hibiscus sabdariffa L. was grown in Da Lat city, Vietnam. After harvested, hibiscus flower was dried at $65{ }^{\circ} \mathrm{C}$ to reach the moisture content of $10 \%$. Materials were then ground and passed through a 60-mesh sieve.

\section{Preparation of Roselle calyx extracts}

Determination of total phenolic content (TPC): Total polyphenol content was determined using Folin-Ciocalteu (FC) reagent [22]. The ethanol extract $(10 \mathrm{mg})$ was dissolved in methanol $(2 \mathrm{~mL})$. The plant extract $(200 \mu \mathrm{L})$ was taken in a test tube and add $10 \%$ Folin-Ciocalteu reagent $(1.5 \mathrm{~mL})$. Then all the test tubes were kept in dark at room temperature for 5 min. Finally, $5 \% \mathrm{Na}_{2} \mathrm{CO}_{3}(1.5 \mathrm{~mL})$ was added to the solution and mixed well. The tube was kept again in the dark for $2 \mathrm{~h}$. The absorbance was measured at $760 \mathrm{~nm}$ through UV-spectrophotometer, with gallic acid as a standard. The total polyphenol content was expressed as $\mathrm{mg}$ gallic acid equivalents (GAEs)/g extract.

Determination of total flavonoid content (TFC): The total flavonoid content was determined using aluminum chloride method [23]. The assay mixture consisting of $0.5 \mathrm{~mL}$ of the ethanol extract, $0.5 \mathrm{~mL}$ distilled water and $0.3 \mathrm{~mL}$ of $5 \% \mathrm{NaNO}_{2}$ was kept at $25^{\circ} \mathrm{C}$. This was followed by addition of $0.3 \mathrm{~mL}$ of $10 \% \mathrm{AlCl}_{3}$ immediately. Two milliliters of $1 \mathrm{M} \mathrm{NaOH}$ was then added to the reaction mixture and the absorbance was measured at $510 \mathrm{~nm}$. Quercetin was used as a standard. Total flavonoids content is expressed as mg quercetin equivalence $(\mathrm{QEs}) / \mathrm{g}$ extract.

Determination of total monomeric anthocyanin content (TAC): The total monomeric anthocyanin content was determined using the pH-differential method [24]. After adjusted to $\mathrm{pH} 1.0$ and 4.5 using $0.2 \mathrm{M} \mathrm{KCl}$ and $0.1 \mathrm{M}$ acetate buffer, respectively, the samples were placed in the dark for $15 \mathrm{~min}$ and the absorbance was measured at 520 and $700 \mathrm{~nm}$. The results were expressed as mg cyanidin-3-glucoside equivalent per volume of the sample $(\mathrm{mg} / \mathrm{L})$.

Determination of antioxidant capacity: Based on Braca et al. [25] method, the ferric reducing antioxidant power assay (FRAP) was determined. First, prepared by mixing $0.3 \mathrm{M}$ acetate buffer (pH 3.6), $0.01 \mathrm{M} \mathrm{TPTZ}$ solution prepared in $0.04 \mathrm{M} \mathrm{HCl}$ and $0.02 \mathrm{M} \mathrm{FeCl} 3$ solution by volumetric ratio of $10: 1: 1$, respectively. Next, $150 \mu \mathrm{L}$ sample was added to $2850 \mu \mathrm{L}$ of FRAP reagent solution to total volume of $3000 \mu \mathrm{L}$. Then, shaken and incubated for $30 \mathrm{~min}$ in the dark and the maximum absorbance was then recorded at $593 \mathrm{~nm}$. Similarly, The DPPH free radical was measured at $515 \mathrm{~nm}$ after $30 \mathrm{~min}$. The results were expressed in $\mathrm{mg}$ Trolox equivalent per volume of the sample ( $\mu \mathrm{mol} \mathrm{TE} / \mathrm{L})$.

The reducing power was determined using the method described by Oyaizu [26]. First, adding $0.1 \mathrm{~mL}$ aliquot of extracts into $0.5 \mathrm{~mL}$ of $0.2 \mathrm{M}$ phosphate buffer (pH 6.6), 0.5 $\mathrm{mL}$ of $1 \% \mathrm{~K}_{3}\left[\mathrm{Fe}(\mathrm{CN})_{6}\right]$ and $2.5 \mathrm{~mL}$ of $10 \%$ trichloroacetic acid. Then, adding $1.6 \mathrm{~mL}$ of distilled water and $0.32 \mathrm{~mL}$ of $1 \%$ ferric chloride. The mixture was generally shaken and measured at $700 \mathrm{~nm}$. The reducing power of the extracts was measured and displayed as the slope of the lines representing the dependence of absorbance on the concentration of total extractable phenolics and denoted as the coefficient of reducing power.

Statistical analysis: All determinations were carried out in triplicate and the results were expressed as mean values and standard deviation. One-way analysis of variance (ANOVA) was performed using SPSS 15 (SPSS Inc. Chicago, U.S.A) and differences between samples were compared using Tukey's test $(\mathrm{P}<0.05)$.

\section{RESULTS AND DISCUSSION}

Effects of extraction solvents on TPC and TFC: Natural phenolics show a beneficial impact on health, primarily through antioxidant activity [27]. These compounds have the ability to reduce oxygen levels, prevent oxidation, scavenge hydroxyl 
radicals, bind metal ions [28]. Total phenolic content (TPC) of Roselle using different solvent systems including methanol, ethanol, acetone at different concentration $(50,70$ and $90 \%$ $\mathrm{v} / \mathrm{v})$ are shown in Table-1. TPC of these solvents were ranked in descending order: $50 \%$ ethanol $>50 \%$ methanol $>50 \%$ acetone $=70 \%$ acetone $>$ distilled water $=70 \%$ methanol $>$ $70 \%$ ethanol $>90 \%$ methanol $=90 \%$ acetone $>90 \%$ ethanol. Water solvent was used as the control sample with TPC values of $615.01 \mathrm{mg} \mathrm{GAE} / \mathrm{L}$ ranked at the fourth position and lower than those of $50 \%$ methanol, $50 \%$ ethanol, $50 \%$ acetone. For ethanolic extracts, the phenolic content decreases as the ethanol concentration increases and the highest value of the TPC (762.11 $\mathrm{mg}$ GAE/L) was obtained using $50 \%$ ethanol as the extraction solvent. The similar trend was observed in the case of using methanol and acetone as extraction solvents with the highest TPC at $50 \%$ of 710.46 and $705.40 \mathrm{mg}$ GAE/L, respectively.

These results illustrate that increasing the concentration of water in the solvent will increase the total phenolic and flavonoid contents of resulting extracts which imply higher extraction performance. The fact that phenolics are easily extracted in polar solvents such as aqueous methanol/ethanol/ acetone compared to pure methanol/ethanol/acetone [19,2830]. Using a mixture of water and organic solvent could facilitate the extraction of substances dissolved in water or organic solvents [30]. Therefore, the efficiency of $50 \%$ methanol, ethanol and acetone solvent was higher than that of the water solvent. The result of this experiment was consistent with the results of a number of studies on medicinal plant extraction by aqueous methanol and ethanol [31]. Previous study about the influences of different extraction solvents including water, acetone, methanol, ethanol and $N, N$-dimethyl formamamide at different concentrations of 50,70 and $100 \%$ on TPC of black and black mate tea, suggested that $50 \%$ of the solvents also gave the highest results.

With respect to flavonoids, TFC of these solvents were ranked in descending order: $50 \%$ ethanol $>50 \%$ acetone $=$ $50 \%$ methanol $>70 \%$ methanol $>70 \%$ ethanol $=90 \%$ methanol $=70 \%$ acetone $>$ distilled water $>90 \%$ acetone $=$ $90 \%$ ethanol. Using methanol, ethanol and acetone as extraction solvent also showed similar tendency as TPC, which showed the highest TFC value (508.64 mg RE/L) at $50 \%$ ethanolic extracts. These observations were similar to TPC. The previous study illustrates that $50 \%$ methanol was the effective solvent for TFC of pineapple while $70 \%$ methanol resulted in the guava extracts with the highest TFC value [32].

Effects of extraction solvents on TAC: The results showed that TAC of these solvents were ranked in descending order: $70 \%$ methanol $>70 \%$ ethanol $=70 \%$ acetone $=50 \%$ methanol $>50 \%$ ethanol $>$ distilled water $=90 \%$ methanol $=90 \%$ ethanol $>90 \%$ acetone $=50 \%$ acetone. Of the extraction solvent systems, $70 \%$ methanol resulted in the highest value of TAC $(8.404 \mathrm{mg} / \mathrm{L})$. In contrast to TPC and TFC, TAC of methanolic extracts was reduced at 50 and $90 \%$ and peaked at $70 \%$. The similar results were achieved in case of using 70 $\%$ ethanol and $70 \%$ acetone as extraction solvent (7.517 and $7.726 \mathrm{mg} / \mathrm{L}$, respectively).

Effects of extraction solvents on DPPH free radical scavenging antioxidant activity: Free radicals generated in the body are related to cancer and other chronic diseases. In this study, DPPH, a type of free radicals which is stable at room temperature producing a purple solution in methanol, was used as the oxidative agent. Reduced DPPH concentration by antioxidants leads to loss of colour intensity. Therefore, the degree of discolouration represents the capacity of antioxidation. Using the DPPH assay provides an easy and quick method to evaluate the antioxidant activity.

Regarding methanol solvents, DPPH antioxidant activity at $70 \%$ methanol extract $(869.47 \mu \mathrm{mol} \mathrm{TE} / \mathrm{L})$ was higher than those at 50 and $90 \%$ methanol extracts. On the other hand, increased ethanol concentration resulted in reduced DPPH antioxidant activity. Specifically, the DPPH antioxidant activity reached the highest value of $924.78 \mu \mathrm{mol} \mathrm{TE} / \mathrm{L}$ at $50 \%$ ethanol compared to 924.78 and $643.62 \mu \mathrm{mol}$ TE/L for 70 and $90 \%$ ethanol solvents, respectively. In terms of acetone solvent, increase in concentration of $50 \%$ to $70 \%(927.60-907.96 \mu \mathrm{mol}$ $\mathrm{TE} / \mathrm{L}$ ) showed the inconsiderable difference in DPPH scavenging activity.

All of these data indicated that at $50 \%$ ethanol, $70 \%$ methanol, 50 and $70 \%$ acetone might be effective extraction solvent for Roselle calyx against DPPH scavenging activity evaluation. The previous study which influences of extraction solvent at different concentrations on the DPPH antioxidant

\section{TABLE-1}

EFFECTS OF EXTRACTION SOLVENTS ON TPC, TFC, TAC AND ANDIOXIDANT ACTIVITIES OF ROSELLE EXTRACTS

\begin{tabular}{|c|c|c|c|c|c|c|}
\hline \multirow{2}{*}{$\begin{array}{c}\text { Extraction } \\
\text { solvents (v/v) }\end{array}$} & \multirow{2}{*}{$\begin{array}{c}\text { TPC } \\
(\mathrm{mg} \mathrm{GAE} / \mathrm{L})\end{array}$} & \multirow{2}{*}{$\begin{array}{c}\text { TFC } \\
(\mathrm{mg} \mathrm{RE} / \mathrm{L})\end{array}$} & \multirow{2}{*}{$\begin{array}{l}\text { Anthocyanin } \\
(\mathrm{mg} / \mathrm{L})\end{array}$} & \multicolumn{3}{|c|}{ Antioxidant activity } \\
\hline & & & & DPPH (mol TE/L) & FRAP (mol TE/L) & $\mathrm{CR}(\mathrm{g} / \mathrm{mL})$ \\
\hline Distilled water & $615.01(3.20) \mathrm{a}$ & $277.88(4.57) \mathrm{a}$ & $5.353(0.163) \mathrm{a}$ & $779.92(11.29) \mathrm{a}$ & $2905.96(2.71) \mathrm{a}$ & $1.387(0.050) \mathrm{a}$ \\
\hline \multicolumn{7}{|l|}{ Ethanol } \\
\hline $50 \%$ & $762.11(7.62) b$ & $508.64(10.4) \mathrm{b}$ & $6.884(0.305) b$ & 924.78 (4.58)b & 2928.47 (126.93)a & $1.434(0.030) \mathrm{a}$ \\
\hline $70 \%$ & $579.54(12.05) \mathrm{c}$ & $319.07(7.42) \mathrm{c}$ & $7.517(0.309) \mathrm{c}$ & $643.62(46.73) \mathrm{c}$ & $2272.15(94.58) b$ & $1.647(0.050) \mathrm{b}$ \\
\hline $90 \%$ & $239.78(7.87) \mathrm{d}$ & $160.23(7.37) \mathrm{d}$ & $5.461(0.212) \mathrm{a}$ & $439.59(15.66) \mathrm{d}$ & $1953.08(37.30) \mathrm{c}$ & $1.708(0.011) b$ \\
\hline \multicolumn{7}{|l|}{ Methanol } \\
\hline $50 \%$ & $710.46(12.55) \mathrm{e}$ & $421.71(6.99) \mathrm{e}$ & $7.441(0.354) \mathrm{c}$ & 785.38 (19.76)a & $2829.91(163.61) a$ & $1.471(0.017) \mathrm{a}$ \\
\hline $70 \%$ & $606.01(2.78) \mathrm{a}$ & $373.70(4.72) \mathrm{f}$ & $8.404(0.275) d$ & $869.47(8.33) \mathrm{b}$ & $2887.96(7.49) \mathrm{a}$ & $1.649(0.015) b$ \\
\hline $90 \%$ & 372.82 (11.61)f & $307.59(1.65) \mathrm{c}$ & $5.503(0.293) \mathrm{a}$ & $688.19(26.48) \mathrm{c}$ & $2169.22(7.15) b c$ & $2.588(0.044) \mathrm{c}$ \\
\hline \multicolumn{7}{|l|}{ Acetone } \\
\hline $50 \%$ & 705.40 (4.06)e & $394.68(2.56) \mathrm{g}$ & $4.435(0.172) \mathrm{e}$ & $927.60(12.32) \mathrm{b}$ & $3493.52(124.31) d$ & $1.789(0.123) b$ \\
\hline $70 \%$ & $690.66(8.61) \mathrm{e}$ & $307.13(14.12) \mathrm{c}$ & $7.726(0.233) \mathrm{c}$ & $907.96(16.82) b$ & $3459.22(35.50) \mathrm{d}$ & $1.717(0.015) b$ \\
\hline $90 \%$ & $352.54(9.09) \mathrm{f}$ & $168.24(4.27) \mathrm{d}$ & $4.174(0.149) \mathrm{e}$ & $568.89(10.95) \mathrm{e}$ & $3150.72(9.06) \mathrm{e}$ & $1.801(0.037) b$ \\
\hline
\end{tabular}

Notes: Data are expressed as mean (standard deviation) and values within a column with the same letter are not significantly different $(\mathrm{P}>0.05)$. 
activity of black and black mate tea, the result showed that using $50 \%$ for ethanol solvent and the 50 and $80 \%$ for acetone solvent gave the highest results [33].

Effects of extraction solvents on ferric reducing antioxidant power (FRAP): While DPPH method is based on the free radical scavenging mechanism, the FRAP method is based on the ability to bind metal ions which act as an intermediate agent in the oxidation process [34]. The FRAP values of these solvents were ranked in descending order: $50 \%$ acetone $=70$ $\%$ acetone $>90 \%$ acetone $>50 \%$ ethanol $=$ distilled water $=$ $70 \%$ methanol $=50 \%$ methanol $>70 \%$ ethanol $>90 \%$ methanol $>90 \%$ ethanol. For methanolic extracts, the highest value of the FRAP was obtained using 50 and $70 \%$ methanol as extraction solvent (2829.91-2887.96 $\mu \mathrm{mol} \mathrm{TE} / \mathrm{L})$. For ethanolic extracts, the FRAP values decrease as the ethanol concentration increases and the highest value of the FRAP (2928.47 $\mu \mathrm{mol}$ TE/L) was obtained using $50 \%$ ethanol as an extraction solvent. On the other hand, in acetone extracts, using 50 and $70 \%$ acetone resulted in the high values. When determining the FRAP value of different solvents, the use of water as extraction solvent produced extracts with similar results compared to methanol and ethanol solvents. In addition, an increase in methanol and ethanol solvent concentration resulted in the reduction of the FRAP values. Generally, acetone was the potent solvent for the FRAP antioxidant capacity. We have recently studied which investigated the influences of extraction solvent at different concentrations on the FRAP antioxidant activity of pineapple, the results revealed that using $50 \%$ concentrations of the acetone gave the highest results [32].

Effects of extraction solvents on reducing power: Reducing power method depends on the reduction of $\mathrm{Fe}^{3+}$ ions in potassium molecule ferricyanide $\left(\mathrm{K}_{3}\left[\mathrm{Fe}(\mathrm{CN})_{6}\right]\right)$ into ion $\mathrm{Fe}^{2+}$ in the molecule of potassium ferrocyanide $\left(\mathrm{K}_{4}\left[\mathrm{Fe}(\mathrm{CN})_{6}\right]\right)$. When adding $\mathrm{FeCl}_{3}, \mathrm{Fe}^{3+}$ will react with ferrocyanide ion to form the complex blue ferricferrocyanide $\left(\mathrm{K}_{4}\left[\mathrm{Fe}(\mathrm{CN})_{6}\right]_{3}\right)$. The values of reducing the power of the solvent extraction of antioxidants from Roselle calyx are shown in Table- 1 . The various solvents are extracted that have asignificantly different function $(\mathrm{P}<$ 0.05 ) in reducing power.

The reducing power values of these solvents were ranked in descending order: $90 \%$ methanol $>50 \%$ acetone $=70 \%$ acetone $=90 \%$ acetone $=70 \%$ ethanol $=90 \%$ ethanol $=70$ $\%$ methanol $>50 \%$ ethanol $=50 \%$ methanol $=$ distilled water. In methanolic extracts, the highest reducing power values were reached at a concentration of $90 \%(2.588 \mathrm{mg} / \mathrm{mL})$. For ethanol solvents, concentrations of 70 and $90 \%$ gave the highest value $(1.647-1.708 \mathrm{mg} / \mathrm{mL})$ and the lowest value was achieved using $50 \%$ ethanol as an extraction solvent. Finally, in acetone extracts, the similar results were obtained as using acetone solvent at concentrations of $50 \%, 70 \%$ and $90 \%$. This might indicate that equivalent to the extraction efficiency of acetone solvent.

\section{Conclusion}

It is found that the solvent used in the extraction of Hibiscus sabdariffa $\mathrm{L}$. significantly affected total anthocyanin content, total phenolic content, total flavonoid content and the antioxidant of the extract. When increasing the concentration of solvent from $50 \%$ to $90 \%$, the measured value of TPC, TFC, FRAP and DPPH antioxidant activity were reduced. In response to increasing DPPH antioxidant activity of methanolic extracts, the decrease in total phenolic content was observed. Total flavonoid content and the antioxidant capacity were found to be increasing with solvent concentration. A $50 \% \mathrm{v} / \mathrm{v}$ ethanol was the most efficient solvents for extracting phenolics (762.11 $\mathrm{mg} \mathrm{RE} / \mathrm{L}$ ) and flavonoids (508.64 mg RE/L) from Roselle calyx, while $70 \%$ methanol was the most efficient solvent system for the extraction of anthocyanins $(8.404 \mathrm{mg} / \mathrm{L})$. Moreover, concerning DPPH free radical scavenging activity, extraction using $50 \%$ ethanol, $70 \%$ methanol, $50 \%$ acetone and $70 \%$ acetone resulted in the highest values than those of the other solvent systems (869.47-927.60 $\mu \mathrm{mol} \mathrm{TE} / \mathrm{L})$. Both $50 \%$ and $70 \%$ acetone were also the most effective solvents yielding the highest ferric reducing antioxidant power FRAP (3493.52$3459.22 \mu \mathrm{mol} \mathrm{TE} / \mathrm{L})$.

\section{CONFLICT OF INTEREST}

The authors declare that there is no conflict of interests regarding the publication of this article.

\section{REFERENCES}

1. M. Ali, J. Chin. Integr. Med., 9, 626 (2011); https://doi.org/10.3736/jcim20110608.

2. Royal College of Physicians and Surgeons of Canada, Royal College of Physicians and Surgeons of Canada, Ottowa (2006).

3. H. Liu, W. Jiang and M. Xie, Recent Patents Anticancer. Drug Discov., 5, 152 (2010); https://doi.org/10.2174/157489210790936261.

4. R.E. Wrolstad, J. Food Sci., 69, C419 (2004); https://doi.org/10.1111/j.1365-2621.2004.tb10709.x.

5. J.-M. Kong, L.-S. Chia, N.-K. Goh, T.-F. Chia and R. Brouillard, Phytochemistry, 64, 923 (2003);

https://doi.org/10.1016/S0031-9422(03)00438-2.

6. P. Bridle and C.F. Timberlake, Food Chem., 58, 103 (1997); https://doi.org/10.1016/S0308-8146(96)00222-1.

7. C. Manach, A. Scalbert, C. Morand, C. Rémésy and L. Jiménez, Am. J. Clin. Nutr., 79, 727 (2004); https://doi.org/10.1093/ajen/79.5.727.

8. C. Manach, G. Williamson, C. Morand, A. Scalbert and C. Rémésy, Am. J. Clin. Nutr., 81, 230S (2005); https://doi.org/10.1093/ajcn/81.1.230S.

9. V. Cheynier, Am. J. Clin. Nutr., 81, 223S (2005); https://doi.org/10.1093/ajcn/81.1.223S.

10. C. Proestos, A. Bakogiannis, C. Psarianos, A.A. Koutinas, M. Kanellaki and M. Komaitis, Food Control, 16, 319 (2005); https://doi.org/10.1016/j.foodcont.2004.03.011

11. E. Middleton Jr. and C. Kandaswami, Biochem. Pharmacol., 43, 1167 (1992); https://doi.org/10.1016/0006-2952(92)90489-6.

12. H. Groot and U. Rauen, Fundam. Clin. Pharmacol., 12, 249 (1998); https://doi.org/10.1111/j.1472-8206.1998.tb00951.x.

13. P.-J. Tsai, J. McIntosh, P. Pearce, B. Camden and B.R. Jordan, Food Res. Int., 35, 351 (2002); https://doi.org/10.1016/S0963-9969(01)00129-6.

14. J.F. Morton, C.F. Dowling and J.F. Morton, Distributed by Creative Resources Systems, Winterville, N.C.: Miami, FL (987).

15. H.D. Neuwinger, African Traditional Medicine: A Dictionary of Plant Use and Applications, Medpharm Scientific Publishers: Stuttgart (2000).

16. I.A. Khan and E.A. Abourashed, Leung's Encyclopedia of Common Natural Ingredients: Used in Food, Drugs and Cosmetics, John Wiley \& Sons, Inc.: Hoboken, N.J, edn 3 (2010).

17. U. Chavan, F. Shahidi and M. Naczk, Food Chem., 75, 509 (2001); https://doi.org/10.1016/S0308-8146(01)00234-5.

18. A.H. Goli, M. Barzegar and M.A. Sahari, Food Chem., 92, 521 (2005); https://doi.org/10.1016/j.foodchem.2004.08.020.

19. F. Anwar, A. Jamil, S. Iqbal and M.A. Sheikh, Grasas Aceites, 57, 189 (2006); https://doi.org/10.3989/gya.2006.v57.i2.36. 
20. M. Abdille, R. Singh, G. Jayaprakasha and B. Jena, Food Chem., 90, 891 (2005); https://doi.org/10.1016/j.foodchem.2004.09.002.

21. R. Celano, A.L. Piccinelli, I. Pagano, G. Roscigno, L. Campone, E. De Falco, M. Russo and L. Rastrelli, Food Res. Int., 99, 298 (2017); https://doi.org/10.1016/j.foodres.2017.05.036.

22. E.A. Ainsworth and K.M. Gillespie, Nat. Protoc., 2, 875 (2007); https://doi.org/10.1038/nprot.2007.102.

23. Y. Gong, Z. Hou, Y. Gao, Y. Xue, X. Liu and G. Liu, Food Bioprod. Process., 90, 9 (2012) https://doi.org/10.1016/i.fbp.2010.12.004

24. M.M. Giusti and R.E. Wrolstad, Current Protocols in Food Analytical Chemistry, Wiley, pp. F1.2.1-F1.2.13 (2001). https://doi.org/10.1002/0471142913.faf0102s00.

25. N. Cardullo, V. Muccilli, R. Saletti, S. Giovando and C. Tringali, Food Chem., 268, 585 (2018); https://doi.org/10.1016/j.foodchem.2018.06.117.

26. M. Oyaizu, Eiyogaku Zasshi, 44, 307 (1986); https://doi.org/10.5264/eiyogakuzashi.44.307.

27. Y.-Z. Fang, S. Yang and G. Wu, Nutrition, 18, 872 (2002); https://doi.org/10.1016/S0899-9007(02)00916-4.
28. M. Naczk and F. Shahidi, J. Chromatogr. A, 1054, 95 (2004); https://doi.org/10.1016/S0021-9673(04)01409-8.

29. B. Sultana, F. Anwar and R. Przybylski, Food Chem., 104, 1106 (2007); https://doi.org/10.1016/j.foodchem.2007.01.019.

30. Q.D. Do, A.E. Angkawijaya, P.L. Tran-Nguyen, L.H. Huynh, F.E. Soetaredjo, S. Ismadji and Y.-H. Ju, J. Food Drug Anal., 22, 296 (2014); https://doi.org/10.1016/j.jfda.2013.11.001.

31. B. Sultana, F. Anwar and M. Ashraf, Molecules, 14, 2167 (2009); https://doi.org/10.3390/molecules14062167.

32. N. Turkmen, F. Sari and Y.S. Velioglu, Food Chem., 99, 835 (2006); https://doi.org/10.1016/j.foodchem.2005.08.034.

33. W. Brand-Williams, M.E. Cuvelier and C. Berset, LWT-Food Sci. Technol., 28, 25 (1995); https://doi.org/10.1016/S0023-6438(95)80008-5.

34. K. Zhou and L. Yu, LWT-Food Sci. Technol., 37, 717 (2004); https://doi.org/10.1016/j.lwt.2004.02.008.

35. I.F.F. Benzie and J.J. Strain, Anal. Biochem., 239, 70 (1996); https://doi.org/10.1006/abio.1996.0292.

36. M. Alothman, R. Bhat and A.A. Karim, Food Chem., 115, 785 (2009); https://doi.org/10.1016/j.foodchem.2008.12.005. 